\title{
Experimental Application of Machine Learning on Financial Inclusion Data for Governance in Eswatini
}

\author{
Boluwaji A. Akinnuwesi ${ }^{(\bowtie)}$, Stephen G. Fashoto, Andile S. Metfula, \\ and Adetutu N. Akinnuwesi \\ Department of Computer Science, University of Eswatini, Kwaluseni, Swaziland \\ moboluwaji@gmail.com
}

\begin{abstract}
An objectives of good governance is to increase capital base of small scale businesses (SSB) in order to encourage more investments and hence increase employment rate. Embracing good financial inclusion (FI) schemes in a country helps to ensure that entrepreneurs of SSB have access to financial services and hence meet their needs. In this paper we studied FI scheme in Kingdom of Eswatini with the view to establish the extent to which SSB have access to funds in running their businesses such that they could satisfy the target population and meet their desired goals. We got FI dataset for Eswatini for 2018 from Finscope database. Finscope 2018 dataset contains 1385 attributes with 2928 records. This study extracted attributes based on payment channel, registered/unregistered business, usage of commercial banks/insurance/mobile money and source of income for households from the Finscope database. We identified lot of missing data and hence replaced them using Mode method of preprocessing module in WEKA. We split the datasets and carried out cross validation on it. Training data is $80 \%$ of the datasets and $20 \%$ was used for testing. We carefully classified FI for selected parameters for Hhohho, Manzini, Shiselweni and Lubombo regions of Eswatini using Logistic regression with $80 \%$ for training and 10 fold cross-validation. The best 10 fold cross-validation recall rate for Manzini region using support vector machine (SVM) is $69.4 \%$ and $63.4 \%$ using logistic regression. These results show that veracity of FI dataset is weak and this is due to large number of missing data.
\end{abstract}

Keywords: Financial inclusion $\cdot$ Machine learning $\cdot$ Governance $\cdot$ Small scale business $\cdot$ Low-income earner

\section{Introduction}

Business is about producing, selling and buying of goods and services with the view to making money. It is an organized effort(s) of an individual or group of individuals that team up to produce and sell goods and services [1]. The ultimate goal in business is making profit, however some businesses can be for non-profit and hence operate for charitable purposes. Every business organization, small scale, medium scale or large scale, needs valuable FI. Financial inclusion particularly for small scale businesses play very import role when it comes to business governance vis-à-vis meeting the needs of 
the target audience and customers [2]. Adequate understanding and proper representation of FI data paves way for good business analytics for proper decision making in business organizations [3].

Financial inclusion is the ability of business entrepreneurs to access financial products and services with the view to satisfy the need of their clients or customers [4]. It has to do with saving, making and receiving payments, transacting, receiving credit, and insurance [5]. It is needed for all business organizations especially the small scale businesses in the developing nations. The inclusion helps the small scaled companies to access credits that could be invested in their businesses. It also helps in saving of cash such that future investments or response to unforeseeable risks can be carried out [6]. Financial inclusion improves the access to insurance products and services which are critical towards addressing vulnerabilities in businesses [7]. Therefore one of the elements of good governance in any country is to have adequate FI schemes for small scale businesses with view to (1) improve production of good and services; (2) increase employment rate and vis-à-vis the standard of living of the people.

The governance of a country relies so much on data aggregated from all private organizations, agencies and government parastatals. Decision making is based on these data [8]. Data grow geometrically in different forms in terms of structure, size, semantics, varieties etc. Therefore this increases the complexity of data and hence use of traditional database management system for data management becomes a challenge. Thus big data technology evolved to help organizations and government collect, organize, represent, process, and analyse data from many sources with the view to reducing cost and time; optimizing the use of resources and developing new products; and making smart decisions [9]. Financial inclusion dataset are big datasets and they are always needed by both private and public sectors. The datasets are diverse in terms of Volume, Velocity, Variety, Variability, Veracity, Visualization, and Value (i.e. 7 V's of Big Data) [10]. Thus, in this paper, we focus on the analysis of the financial inclusion dataset for Eswatini with the view to carefully classify FI data set based on selected parameters for Hhohho, Manzini, Shiselweni and Lubombo regions of Eswatini using Logistic regression (LR) and SVM. Machine learning technique has been identified to be very useful for analysis of government-based data and hence infer relevant hidden facts from them [11].

The paper is organized as follows: Sect. 2 present the general overview of the Kingdom of Eswatini vis-à-vis financial inclusion in the context of Eswatini. Review of related works is presented Sect. 3. Methodology is presented in Sect. 4 while result is presented in Sect. 5. Conclusion is presented in Sect. 6.

\section{General Overview of Financial Inclusion in the Kingdom of Eswatini (Formerly Swaziland)}

Eswatini is a growing economy and it is a Southern African country with a current population of $1,154,514$ which is equivalent to $0.01 \%$ of the total world population as of January 10, 2020, based on the United Nations estimates [12]. It is a landlocked country in Southern Africa with total land area of approximately 17,200 Km2 (6,641 sq. miles) [12]. The Gross Domestic Product (GDP) per capital is 3,914.02 US dollars 
in 2017 and in the long-term, the Swaziland GDP per capita is projected to trend around 3,955.07 USD in 2020, according to World Bank econometric models. The ease of doing business is ranked 112 as at 2017. The country is ranked as middle-income country and is committed to a free market economy and private ownership.

The governments in the African continent have realized the pivotal role that FI plays in combatting poverty and contributing to inclusive economic growth by positively impacting on the low income earners and small scale businesses. Hence reducing income inequality and expanding employment. Recent innovations in financial services for small scale business groups has made governments to know how FI could strengthen the resilience of vulnerable and marginalised populations [13]. Thus a number of countries on the African continent have begun to develop national FI strategies and spearhead key programs and initiatives to improve financial markets.

In the light of the above, the Ministry of Finance in Swaziland in 2017, published the FI strategy for the Government of Swaziland (GoS) [13]. This was based on the critical role that GoS attached for FI. The FI journey for GoS dated back to 2010 in which the government through the Ministry of Finance (MoF) established the Micro Finance Unit (MFU) to implement the International Fund for Agricultural Development (IFAD) supported Rural Finance and Enterprise Development Programme (RFEDP) with the view of facilitating access to financial services for the rural population and the micro and small scale businesses. In 2013, Ministry of Finance of GoS joined the Alliance for Financial Inclusion (AFI), which is a global movement on FI and this helps to impact directly on the welfare of people at microeconomic and household levels. It helps to reduce people's transaction costs and hence enabling them to efficiently manage risks, allocating capital for productive use and supporting the accumulation of wealth over time [13]. There are three dimensions of FI: Access, usage and quality. The comprehensive document of the GoS financial inclusion strategy is well presented in [13]. It is expected that the proposed strategy will lead to increase in reach, depth and quality of FI in Swaziland, and a sustainable financial sector that is able to increase citizen welfare, create economic growth, and hence meet national goals. It also presents the level of readiness of the government of Swaziland about financial inclusiveness. In this light few research works have been reported in the recent time on FI as it affect Swaziland.

The qualitative research reported in [14] was an exploratory study to investigate the competitive advantage and the critical success factors of Swaziland (Eswatini) financial cooperatives. Financial cooperatives are means of providing financial services to lowincome earners and hence make them to be in the FI scheme of government. Financial services acquisition journey model in the context of Eswatini was proposed. The model offered an integrated representation whereby financial services are fully extended to low-income earners with the view to access funds and credit facilities and hence guarantees financial inclusiveness for them. Thus financial cooperatives are noted among the distribution channels for credit facilities. This aligns with the interest of United Nations (UN) and International Labour Organization (ILO) towards financial cooperatives as mechanism that should be utilized to promote FI within the low-income earners [15]. However the author in [15] noted the mixed views about the role of savings and credit cooperatives (SACCOs) to facilitate access to financial services for people in Swaziland. Thus it was reported in the research that more knowledge is 
required about role of SACCOs and development of better scheme for quick access to loan and repayment of loan by their members which are mostly low-income earners.

The authors in [16] considered micro-insurance companies as another distribution channel that could make fund and credit accessible to low-income earners in Swaziland and this further helps to ensure wider coverage for FI. Hence they proposed a framework of micro-insurance distribution and implication based on the data collected in Swaziland. Similarly Mngadi noted in the research reported in [17] the role that microfinance institutions played on entrepreneurship in Swaziland. It was recommended that microfinance institutions should focus more on developmental finance for small scale businesses and low-income earner. In [18] crop insurance was identified as another FI scheme. Though it served as a means of protecting farmers against potential losses and hence minimize risk but it was noted in Swaziland that crop insurance is not well developed and implemented due to shallow knowledge of farmers about the preference for crop insurance. Similar study was carried out by Xolile in [19] focusing on livestock insurance. In [20], investment was also identified as one of the key instruments for equitable income distribution to ensure FI but this is also not well explored in low income countries and fragile environment.

\section{Related Works and Deductions}

\subsection{Related Works}

Financial inclusion is a government scheme that is meant to enable citizens to make contribution towards the growth of a country and also make the citizen to make gain from the economic growth [21]. FI is considered as one of the significant indicator of inclusive growth in governance [22]. A number of research works have been done on financial inclusion across the continents. In [23], the authors criticized the unambitious approach that did not include FI as a sustainable goal in 2030 agenda for sustainable development in developing countries. The authors noted that FI was not included as a stand-alone goal among the several sustainable development goals (SDGs). The reasons identified for this are the: instrumentality argument, free market argument, and veil argument. The 2030 agenda was seen as a missed opportunity to focus on finding means to meeting the financial need of the global poor. This implies that in developing economies, the financial bridge between the rich and the poor keep widening as the government fail to extend good governance to the poor through the establishment of a strong financial structure that makes FI to be fully extended to the poor. Similarly in [24] positive influence of mobile micro-insurance on FI in developing countries was investigated and it was established that inclusive financing is more successful in countries that adopt and use mobile micro-insurance compared to countries where such services are not made available to the poor or low-income earners. It is inferred from this study that the use of low-cost mobile channels of micro-insurance would enable low-income earners and small scale businesses to have immediate access to microinsurance and this contributes to financial inclusiveness. Thus governance should be extended to low-cost or rural communities by erecting good infrastructural facilities and making good policies to support establishment of micro-insurance and low-cost 
mobile channels in these areas. Ozili in [25] reviewed digital finance (DF) vis-à-vis FI in the context of developing and emerging economies. It was noted that the mesh of DF and FI has lots of benefits to financial services users, DF providers, government and the economy in general. This corroborates with the study reported in [24]. Célerier and Matray in [26] did a study on the effects of FI on wealth accumulation in the context of USA. The authors studied the USA interstate branching deregulation policy between 1994 and 2005 and established that expansion of the bank branches across the states helped to increase access to funds the low-income earners, hence it increase the lowincome household FI. These studies presented in [22, 27] looked at empowering women through financial inclusion. The authors noted that most of the Indian women that make up $46 \%$ of the India total population are denied opportunities and rights to financial access and this made them to be financially dependent. The authors affirmed that FI is needed for the women in order to pay for micro-insurance and obtain credit from financial institutions. This helps in national development by women improving access to markets and overall empowerment data.

\subsection{Deductions from Literature Review}

a. We deduce from our review that a number of research works have been carried on financial inclusion with the following set of objectives: (1) Development of framework for FI implementation with view to reduce poverty; (2) Review of factors (e.g. social, political, environmental etc.) that could influence financial inclusiveness; (3) The involvement of adult in banking operations with view to having access to credit facilities; (4) Development of financial structure that make FI fully extended to the poor; (5) Government to focus more on encouraging the establishment of micro-insurance institutions.

b. We further deduced that statistical technique was applied in the data analysis with the view to affirm the financial inclusiveness of households, low-income earners and small scale entrepreneurs.

c. In addition, we found out that despite the wide range of research works done on FI across the continents, few were recorded for the Kingdom of Eswatini and these are mostly doctoral theses and masters dissertations reported in universities outside of Eswatini. These research works are mostly exploratory studies that focus mainly on the behaviour of the people (mostly low income earners and small scale entrepreneurs) towards micro-finance, micro-insurance, financial cooperatives and banks. Some also focused on the saving and investment attitude of low-income earners. None of the works access or make use of FI data set for Eswatini and no computational technique is applied in the course of data analysis.

d. We noted that none of these research works relates FI with governance and neither did the authors make use of intelligent techniques such as machine learning techniques for mining the FI data set with the view to extracting more meaningful information that could impact on the governance of the country as per financial distribution, use and proper management. Also none of the works applied data mining or machine learning technique to process the FI data set with the view to understand the data pattern, ascertain the validity and accuracy of the data set. 
In view of the above deduction, we choose in this research to apply machine learning technique for proper pre-processing of FI data set with the aim to clean, validate and classify the data and relate the required attributes of the data set to the governance of the country with regards to financial management (i.e. income distribution through credit facilities and government contribution and use of the income for personal and organizational gains)

\section{Methodology}

\subsection{Dataset Description}

The FinScope dataset is made up of 2928 data objects and 1352 attributes. Table 1 presents the description of the dataset and it shows the selected attributes from the FinScope database based on the objective of this study. The FinScope dataset are categorized based on four region (HhoHho, Manzini, Lubombo and Shiselweni). All data object used in this study has numeric attributes as shown in Table 1.

\subsection{Data Pre-processing}

The data collected was in Microsoft Excel in CSV (comma separated variable) format. After reading the data, the missing data that occurred in the payment channel attributes as displayed in Table 1 was replaced using the Mode method. In the mode method, all the missing attributes value in numeric form is replaced by the most frequent value of the known attribute.

\section{Results}

\subsection{Experimental Results on Logistic Regression and Support Vector Machine}

This section provides a comparison of the logistic regression and support vector machine (SVM) in terms of recall, precision and correctly classified instances.

In this experiment, SPSS and WEKA (Waikato environment for knowledge Analysis) were used. SPSS was used to determine the number of missing data in the selected attributes as display in Table 1 and WEKA was employed for the machine learning techniques (logistic regression and SVM) to determine the classification accuracy. The results of the comparison are given in Tables 2, 3, 4 and 5.

From the matrix in Table 2, the correctly classified financial inclusion from the selected parameters for Hhohho region is 269, 337 is incorrectly classified in Manzini, 83 incorrectly classified in Shiselweni and 87 incorrectly classified in Lubombo. The correctly classified financial inclusion from the selected parameters for Manzini region is 563, 104 is incorrectly classified in Hhohho, 87 incorrectly classified in Shiselweni and 134 incorrectly classified in Lubombo. The correctly classified financial inclusion from the selected parameters for Shiselweni region is 137,80 is incorrectly classified in Hhohho, 250 incorrectly classified in Manzini and 121 incorrectly classified in 
Lubombo. The correctly classified financial inclusion from the selected parameters for Lubombo region is 148,86 is incorrectly classified in Hhohho, 301 incorrectly classified in Manzini and 101 incorrectly classified in Shiselweni.

From the matrix in Table 4, the correctly classified financial inclusion from the selected parameters for Hhohho region is 289, 417 is incorrectly classified in Manzini, 52 incorrectly classified in Shiselweni and 58 incorrectly classified in Lubombo.

Table 1. Description of dataset

\begin{tabular}{|c|c|c|}
\hline $\begin{array}{l}\text { Variable } \\
\text { name }\end{array}$ & $\begin{array}{l}\text { Data } \\
\text { type }\end{array}$ & Description \\
\hline C13B_1 & Numeric & C13b. Payment channel - Food and drink and other groceries \\
\hline C13B_2 & Numeric & C13b. Payment channel - Water/Electricity, paraffin, gas and other fuel \\
\hline C13B_3 & Numeric & $\begin{array}{l}\text { C13b. Payment channel - Education (school fees, university or college fees, } \\
\text { uniform, transport, stationery) }\end{array}$ \\
\hline C13B_4 & Numeric & $\begin{array}{l}\text { C13b. Payment channel - Transport expenses (taxi fare, bus fare, train fare, petrol } \\
\text { for car) }\end{array}$ \\
\hline C13B_5 & Numeric & C13b. Payment channel - Bond or home loan, credit card, car financing \\
\hline C13B_6 & Numeric & $\begin{array}{l}\text { C13b. Payment channel - Communication, e.g., Airtime, cell phone contract, EPTC } \\
\text { telephone line payments, internet payments, data }\end{array}$ \\
\hline C13B_7 & Numeric & $\begin{array}{l}\text { C13b. Payment channel - Medical, health expenses, doctors fees, } \\
\text { pharmacy/chemist medicines }\end{array}$ \\
\hline C13B_8 & Numeric & C13b. Payment channel - Rental payments and rates, levies \\
\hline C13B_9 & Numeric & $\begin{array}{l}\text { C13b. Payment channel - Other debt repayments (e.g. clothing store accounts, hire } \\
\text { purchase) }\end{array}$ \\
\hline C13B_10 & Numeric & C13b. Payment channel - Savings, investments and retirement \\
\hline C13B_11 & Numeric & $\begin{array}{l}\text { C13b. Payment channel - Insurance and Funeral premium payments (e.g., life } \\
\text { insurance, burial society) }\end{array}$ \\
\hline C13B_12 & Numeric & $\begin{array}{l}\text { C13b. Payment channel - Household furnishings, equipment and routine household } \\
\text { maintenance }\end{array}$ \\
\hline C13B_13 & Numeric & $\begin{array}{l}\text { C13b. Payment channel - Personal spending e.g. haircuts, gym, lotto, cigarettes, } \\
\text { alcohol, clothes }\end{array}$ \\
\hline C13B_14 & Numeric & $\begin{array}{l}\text { C13b. Payment channel - Leisure, entertainment and miscellaneous goods and } \\
\text { services }\end{array}$ \\
\hline C13B_15 & Numeric & $\begin{array}{l}\text { C13b. Payment channel - Farming inputs e.g. seeds, feritiliser, equipment, } \\
\text { chemical }\end{array}$ \\
\hline C13B_16 & Numeric & C13b. Payment channel - Business inputs e.g. stock, machinery or equipment \\
\hline A18 & Numeric & A18. Main source of income - for Head of Household \\
\hline Region & Numeric & Region \\
\hline E1_1 & Numeric & E1. Ever used - Commercial bank \\
\hline E1_2 & Numeric & E1. Ever used - Mobile money operator \\
\hline E1_3 & Numeric & E1. Ever used - Cooperative Society \\
\hline E1_4 & Numeric & E1. Ever used - Insurance provider \\
\hline E1_5 & Numeric & E1. Ever used - Pension fund administrator \\
\hline E1_6 & Numeric & E1. Ever used - Microfinance institution \\
\hline
\end{tabular}


Table 2. Matrix on cross-validation based on logistic regression

\begin{tabular}{l|c|l|l|l}
\hline & A = Hhohho & $\mathrm{B}=$ Manzini & $\mathrm{C}=$ Shiselweni & $\mathrm{D}=$ Lubombo \\
\hline $\mathrm{A}=$ Hhohho & 269 & 377 & 83 & 87 \\
\hline $\mathrm{B}=$ Manzini & 104 & 563 & 87 & 134 \\
\hline $\mathrm{C}=$ Shiselweni & 80 & 250 & 137 & 121 \\
\hline $\mathrm{D}=$ Lubombo & 86 & 301 & 101 & 148 \\
\hline
\end{tabular}

Table 3. Matrix on cross-validation based on SVM

\begin{tabular}{l|c|l|l|l}
\hline & A = Hhohho & B = Manzini & C = Shiselweni & D = Lubombo \\
\hline $\mathrm{A}=$ Hhohho & 289 & 417 & 52 & 58 \\
\hline $\mathrm{B}=$ Manzini & 116 & 616 & 74 & 82 \\
\hline $\mathrm{C}=$ Shiselweni & 98 & 295 & 114 & 81 \\
\hline $\mathrm{D}=$ Lubombo & 104 & 361 & 75 & 96 \\
\hline
\end{tabular}

Table 4. Recall on logistic and SVM

\begin{tabular}{l|l|l}
\hline Region & Logistic & SVM \\
\hline HhoHho & 0.33 & 0.354 \\
\hline Manzini & 0.634 & 0.694 \\
\hline Shiselweni & 0.233 & 0.194 \\
\hline Lubombo & 0.233 & 0.151 \\
\hline
\end{tabular}

The correctly classified financial inclusion from the selected parameters for Manzini region is 616, 116 is incorrectly classified in Hhohho, 74 incorrectly classified in Shiselweni and 82 incorrectly classified in Lubombo. The correctly classified financial inclusion from the selected parameters for Shiselweni region is 114, 98 is incorrectly classified in Hhohho, 295 incorrectly classified in Manzini and 81 incorrectly classified in Lubombo. The correctly classified financial inclusion from the selected parameters for Lubombo region is 96, 104 is incorrectly classified in Hhohho, 361 incorrectly classified in Manzini and 75 incorrectly classified in Shiselweni.

From the results on Table 5, it is the Manzini region that has a pass mark for the financial inclusion using the logistic regression and the SVM model. The SVM model outperforms the logistic regression model in terms of the recall while the logistic regression model outperforms the SVM model in term of the correctly classified instances as display in Table 5. 
Table 5. Precision on logistic and SVM

\begin{tabular}{l|l|l}
\hline Region & Logistic & SVM \\
\hline HhoHho & 0.499 & 0.476 \\
\hline Manzini & 0.378 & 0.365 \\
\hline Shiselweni & 0.336 & 0.362 \\
\hline Lubombo & 0.302 & 0.303 \\
\hline
\end{tabular}

From the results on Table 5, it is the HhoHho region that has the highest precision for the financial inclusion using the logistic regression and the SVM.

Table 6. Classification accuracy

\begin{tabular}{l|l|l}
\hline & Logistic regression & SVM \\
\hline Correctly classified & 38.1489 & 38.0806 \\
\hline
\end{tabular}

From the classification accuracy result show on Table 6 it is discovered that after the pre-processing of the replaced missing data in the financial inclusion dataset of 2018 the result is affected negatively due to large missing data in the original dataset. This is the main reason why the accuracy in the two model considered are below $40 \%$. The classification algorithms will only be able to make an informed decision on the dataset if the accuracy is $80 \%$ and above.

\subsection{Inferences}

The following are our inferences based on the study carried out in this research as far as financial inclusion in the kingdom of Eswatini is concern vis-à-vis governance:

a. Statistically, after the pre-processing, it was discovered that over $80 \%$ payment was made by cash while less than $1 \%$ was through the bank. On bank usage, it was discovered that only $47.5 \%$ has used commercial bank, $66.4 \%$ used mobile money, $7.2 \%$ used cooperative society, $10 \%$ used insurance, $4.9 \%$ used pension fund and $0.9 \%$ used microfinance. Most households in local communities does not have bank account so government need to come up with a policy to encourage cashless society that will also give room for credit accessibility and use of financial institution.

b. From the classification algorithm in machine learning, the recall result in Table 3 is an indication that the government of Eswatini need to pay more attention to enhance financial inclusion in the these three regions (HhoHho, Shiselweni and Lubombo) with more attention on Lubombo.

c. It was discovered in this study that $66.7 \%$ of the household in low-income earning communities make use of mobile money for making payment then the government need to consider mobile money as part of the key indicator for financial inclusion.

d. The government also need to encourage head of household on the importance of business registration since only $3.8 \%$ registered their businesses. 
e. Research in this area is few in Swaziland and this is attested to by Zikalala in [15] and Kanyangale [16].

f. Low-income earners and small scale entrepreneurs should be encouraged to bank in order to have access to credit facilities with the view to expand FI and thus have all the low-income earners included. Similar recommendation was made in [19].

g. Financial empowerment programmes are recommended to train people in various households on investment vis-à-vis financial management. Such programmes open up the credit opportunities in financial institutions (i.e. Banks, Microfinance, Microinsurance, Financial cooperatives etc.) and how they can be accessible to lowincome earners. This is similar to the recommendations stated in [28, 29].

\section{Conclusion}

Presently in Africa there is so much interest to promote financial inclusion based on the commitment of so many countries to financial inclusion action plan to reduce poverty and grow their economy [26, 30]. But Africa as a continent is lagging behind other continents in financial inclusion because inclusive development is left out [5, 31]. Our findings in this study show that there is still need to revamp the financial inclusion datasets on the demand-side using machine learning methods for exploring different pre-processing algorithms to eliminate the remaining outliers in the dataset to improve the classification accuracy which is yet to be looked into critically due to lack of data quality. A better classification can only be achieved when there is good quality of data. The Confusion matrix was discussed in this paper using logistic regression and SVM to classify the actual and observations (true positive, true negative, false negative and false positive) from the payment channel, registered/unregistered/licensed business, usage of commercial banks, mobile money, insurance, microfinance, cooperative society and source of income for head of household. The results show that the veracity of the financial inclusion dataset is weak and this is due to the fact that the precision and recall rate is less than $50 \%$ and $70 \%$ respectively. Therefore, it is expedient to separate the demand-side data from the supply side data from the entire dataset and also to employ different pre-processing approaches or data transformation techniques to improve the quality of the data which will automatically improve the classification accuracy. The misclassification of the features misrepresents the causes underlying financial inclusion due to the precision rate against the recall rate.

\section{References}

1. Adam, H.: Business (2019). https://www.investopedia.com/terms/b/business.asp. Accessed 11 Jan 2020

2. Färber, F., Cha, S.K., Primsch, J., Bornhövd, C., Sigg, S., Lehner, W.: SAP HANA database: data management for modern business applications. ACM SIGMOD Rec. 40(4), 45-51 (2012)

3. Choi, T.-M., Chan, H.K., Yue, X.: Recent development in big data analytics for business operations and risk management. IEEE Trans. Cybern. 47(1), 81-92 (2016) 
4. Sarma, M., Pais, J.: Financial inclusion and development. J. Int. Dev. 23(5), 613-628 (2011)

5. Demirguc-Kunt, A., Klapper, L.: Measuring financial inclusion: the Global Findex Database. The World Bank (2012)

6. Atkinson, A., Messy, F.-A.: Promoting financial inclusion through financial education: OECD/INFE evidence, policies and practice. In: OECD Working Papers on Finance, Insurance and Private Pensions, vol. 34, no. 1, pp. 1-55 (2013)

7. Demirgüç-Kunt, A., Klapper, L.: Measuring financial inclusion: explaining variation in use of financial services across and within countries. Brookings Pap. Econ. Act. 2013(1), 279340 (2013)

8. Provost, F., Fawcett, T.: Data science and its relationship to big data and data-driven decision making. Big Data 1(1), 51-59 (2013)

9. SAS: "Big Data: What it is and why it matters," SAS Insight (2019). https://www.sas.com/ en_us/insights/big-data/what-is-big-data.html. Accessed 11 Jan 2020

10. Oussous, A., Benjelloun, F.-Z., Lahcen, A.A., Belfkih, S.: Big data technologies: a survey. J. King Saud Univ. Comput. Inf. Sci. 30(4), 431-448 (2018)

11. Kleinberg, J., Ludwig, J., Mullainathan, S.: A guide to solving social problems with machine learning. Harvard Business Review (2016). http://www.zeshiyang.com/images/Social\% 20Problems\%20with\%20Machine\%20Learning.pdf. Accessed 10 Jan 2020

12. Worldometer: Eswatini (Swaziland) Population (2020). https://www.worldometers.info/ world-population/swaziland-population/. Accessed 11 Jan 2020

13. Ministry-of-Finance: National Financial Inclusion Strategy for Swaziland 2017-2022 (2017). https://www.afi-global.org/sites/default/files/publications/2018-01/Swaziland\%20National\% 20Financial\%20Inclusion\%20Strategy\%202017\%20-2022.pdf. Accessed 13 Jan 2020

14. Mashwama, J.: The competitive advantages of and critical success factors for financial cooperatives in Swaziland, Gordon Institute of Business Science, University of Pretoria. M. Sc. dissertation (2014)

15. Zikalala, M.J.: The role of savings and credit cooperatives in promoting access to credit in Swaziland, Agricultural Economics, Faculty of Natural and Agricultural Sciences, University of Pretoria (2016)

16. Kanyangale, M., Lukhele, M.: Pathways to the poor in Swaziland: what is the nature of micro insurance channels and distribution strategy? Afr. J. Bus. Manag. 12(14), 439-450 (2018)

17. Mngadi, W.P.: The role of microfinance institutions on entrepreneurship development: the case of Swaziland, Law and Management, Wits Business School, Faculty of Commerce, University of the Witwatersrand, Ph.D. thesis (2016)

18. Mbonane, N.D.: An analysis of farmers' preferences for crop insurance: a case of maize farmers in Swaziland, Department of Agricultural Economics, Extension \& Rural Development, Faculty of Natural and Agricultural Science, University of Pretoria, M.Sc. dissertation (2018)

19. Mamba, T.X.: The role of contracts in improving access to credit in the smallholder livestock sector of Swaziland, Agricultural Economics, Faculty of Natural and Agricultural Sciences, University of Pretoria, M.Sc. dissertation (2016)

20. Msibi, M.N.: The relationship between monetary attitudes and investment behaviour among teachers in Swaziland. School of Business, University Of Nairobi, M.Sc. dissertation (2017)

21. Kapoor, A.: Financial inclusion and the future of the Indian economy. Futures 56(1), 35-42 (2014)

22. Subha, S., Unni, A.: Women empowerment and financial inclusion. Heritage 68(2), 33-38 (2020)

23. Fu, J., Queralt, J., Romano, M.: Financial inclusion and the 2030 agenda for sustainable development: a missed opportunity. Enterp. Devel. Microfinan. 28(3), 200-211 (2017) 
24. Chummun, B.Z.: Mobile microinsurance and financial inclusion: the case of developing African countries, Africa growth Agenda, July/September 2017, vol. 2017, pp. 12-16 (2017)

25. Ozili, P.K.: Impact of digital finance on financial inclusion and stability. Borsa Istanbul Rev. 18(4), 329-340 (2018)

26. Célerier, C., Matray, A.: Bank-branch supply, financial inclusion, and wealth accumulation. Rev. Finan. Stud. 32(12), 4767-4809 (2019)

27. Chandradevi, P., Sounderya, P.P., Sudarvizhli, S.: Women empowerment and financial inclusion. Heritage 68(2), 477-486 (2020)

28. Brixiová, Z., Kangoye, T.: Gender and constraints to entrepreneurship in Africa: new evidence from Swaziland. J. Bus. Ventur. Insights 5(2), 1-8 (2016)

29. Brixiová, Z., Kangoye, T.: Skills as a barrier to women's start ups: a model with evidence from Eswatini. In: ERSA Working Paper 768, Economic Research Southern Africa (ERSA) (2018). https://www.researchgate.net/profile/Zuzana_Brixiova/publication/329512410_Skill s_as_a_Barrier_to_Women's_Start_Ups_A_Model_with_Evidence_from_Eswatini/links/5c 0ff03d299bf139c752152a/Skills-as-a-Barrier-to-Womens-Start-Ups-A-Model-with-Evidenc e-from-Eswatini.pdf. Accessed 25 Jan 2020

30. Ahamed, M.M., Mallick, S.K.: Is financial inclusion good for bank stability? International evidence. J. Econ. Behav. Organ. 157(1), 403-427 (2019)

31. Dev, S.M.: Financial inclusion: issues and challenges. Econ. Polit. Wkly 41(41), 4310-4313 (2006) 